\title{
General and abdominal adiposity in a representative sample of Portuguese adults: dependency of measures and socio-demographic factors' influence
}

\author{
Joanna Kowalkowska ${ }^{1}$, Rui Poínhos ${ }^{2}$, Bela Franchini ${ }^{2,3}$, Cláudia Afonso, ${ }^{2,3}$, Flora Correia ${ }^{2,3,4,5}$, \\ Sílvia Pinhão ${ }^{2,4}$, Maria Daniel Vaz de Almeida ${ }^{2,3}$ and Sara Rodrigues ${ }^{2,3,6,7 *}$ \\ ${ }^{1}$ Department of Human Nutrition, Faculty of Food Sciences, University of Warmia and Mazury in Olsztyn, Stoneczna 44a, \\ 10-718 Olsztyn, Poland \\ ${ }^{2}$ Faculty of Nutrition and Food Sciences, University of Porto, Rua Dr Roberto Frias, 4200-465 Porto, Portugal \\ ${ }^{3}$ Portuguese Society of Nutrition and Food Sciences (SPCNA), Apartado 2528, 4200-401 Porto, Portugal \\ ${ }^{4}$ Centro Hospitalar de S. João, E.P.E., Al. Prof. Hernâni Monteiro 4200-319 Porto, Portugal \\ ${ }^{5}$ Unidade de Investigação e Desenvolvimento de Nefrologia (UIDN), Al. Prof. Hernâni Monteiro 4200-319 Porto, Portugal \\ ${ }^{6}$ Laboratório associado para a química verde - tecnologias e processos limpos (LAQV-REQUIMTE), Apartado 55142, 4051-401 \\ Porto, Portugal \\ ${ }^{7}$ EPIUnit/Institute of Public Health, University of Porto, Rua das Taipas 135, 4050-600 Porto, Portugal
}

(Submitted 9 March 2015 - Final revision received 28 August 2015 - Accepted 15 September 2015 - First published online 22 October 2015)

\section{Abstract}

The aims of this study were: (i) to estimate the dependency between BMI and waist:height ratio (WHtR) as measures of general and abdominal adiposity, and (ii) to evaluate the influence of socio-demographic factors on both measures and on their dependency in risk classification. Data from a cross-sectional study conducted in 2009 among a representative sample of 3529 Portuguese adults were used. Height, weight and waist were measured and socio-demographic data (sex, age, education level, occupational status, marital status, region of residence) were obtained. Using logistic regression, crude and adjusted OR for high general (BMI $\geq 25.0 \mathrm{~kg} / \mathrm{m}^{2}$ ) and abdominal (WHtR $\geq 0 \cdot 5$ ) adiposity, and for incompatible classification between them, were calculated. Above half (50.8\%) of the respondents had high BMI and $42 \cdot 1 \%$ had high WHtR, and the rates were higher in men than in women. There was an inverse association between education level and both adiposity measures. The lowest prevalence of high general and abdominal adiposity was observed in students and singles, whereas the highest was found in retired, widowed and respondents from Azores, Madeira and Alentejo. Nearly a quarter of respondents (24.0\%) were incompatibly classified by BMI and WHtR, with higher prevalence in men than in women and in low- than in high-educated people. Future surveys should focus on developing at least sex-specific cut-offs for both measures. Implementation of effective strategies for preventing and reducing high adiposity levels in Portugal should be directed primarily to men, older, low-educated individuals, as well as those living in the islands and poor regions of the country.

\section{Key words: Socio-demographic factors: Obesity: Abdominal adiposity: Waist:height ratio: BMI}

The prevalence of overweight and obesity in the world is growing every year ${ }^{(1)}$. In Europe, in particular, geographic variation in obesity occurrence was observed, with the rates being higher in central, eastern and southern countries than in northern and western ones ${ }^{(2,3)}$. On the basis of the European Nutrition and Health Report 2009, overweight and obesity prevalence was the highest in Cypriot men (83\%) and Greek women (73\%) and the lowest in Dutch men (42\%) and Norwegian and Austrian women $(31 \%)^{(3)}$. In Portugal, two representative national surveys conducted in 1995-1998 and 2003-2005 showed that overweight and obesity prevalence in adults increased from $49 \cdot 6$ to $53 \cdot 6 \%{ }^{(4)}$. Between 2004 and 2009 , the same rates increased from 54 to $60 \%$ in men and from 46 to $49 \%$ in women ${ }^{(3)}$. The prevalence of obesity in Portuguese adults increased about $20 \%$ (from $12 \cdot 8$ to $15 \cdot 4 \%$ ) between 2000 and $2010^{(5)}$.

Because of substantial health consequences, as an important risk factor of non-communicable diseases (NCD) that entails high costs of treatment, the increasing prevalence of overweight and obesity is one of the most important challenges in public health $^{(1,3,5,6)}$. The World Health Organization ${ }^{(1)}$ reported that in the past 10 years the occurrence of NCD risk factors has significantly increased among adults. In Portugal, in the year 2009, $24.6 \%$ of adults had low physical activity and $43.7 \%$ were smokers ${ }^{(7)}$.

The primary cause of overall overweight is imbalance between energy intake and expenditure ${ }^{(8)}$. However, many different socio-demographic and lifestyle factors are also involved, including sex, age, region, socio-economic status

Abbreviations: SES, socio-economic status; WC, waist circumference; WHtR, waist:height ratio.

* Corresponding author: Assistant Professor S. Rodrigues, fax +351 225074329, email saraspr@fcna.up.pt 
(SES), physical inactivity or smoking habits ${ }^{(2,5,9)}$. Prevalence of obesity and inequalities in health are steadily increasing, especially among individuals with low $\operatorname{SES}^{(1,6)}$. Numerous studies reported that the association between SES and obesity is inverse in developed countries, but it is direct in developing countries $^{(10,11)}$. For occupational status, in developed countries, the association with overweight was inverse and relatively consistent in both sexes. For education level, this association was slightly less consistent in men, but for income it was inconsistent for both men and women ${ }^{(10)}$. Socio-economic inequalities are an important cause of overweight due to a substantial influence on food choices and physical activity. The high-energy-dense and low-nutritional diet, sedentary lifestyles and psychosocial factors increase obesity risk, especially among people with low $\mathrm{SES}^{(6)}$.

The BMI as an indicator of general adiposity and the waist: height ratio (WHtR) as an indicator of abdominal adiposity are commonly used in the assessment of body weight status ${ }^{(8,12)}$. However, some studies have demonstrated that WHtR is a better predictor of disease or mortality risk than $\mathrm{BMI}^{(13,14)}$. There are many studies regarding the influence of demographic, socio-economic and lifestyle factors on overweight assessed by $\mathrm{BMI},{ }^{(9-11,15-17)}$ but, in accordance with our best knowledge, there are only few corresponding to large and comprehensive researches concerning sociodemographic determinants of general and abdominal obesity in Portugal ${ }^{(4,18,19)}$ or in Europe ${ }^{(20,21)}$. Therefore, the aims of this study were as follows: (i) to estimate the dependency between BMI and WHtR in assessing adiposity, and (ii) to evaluate the influence of socio-demographic factors on both measures and on their dependency in risk classification. Analysing the dependency between BMI and WHtR intends to estimate the proportion of incompatible classification between them and to spot the groups with a higher probability of misclassification. By identifying the socio-demographic factors influencing BMI and WHtR, it is meant to point out the groups more prone to present higher prevalence of adiposity levels, in order to better shape effective national strategies for the prevention and reduction of high adiposity levels and its health consequences.

\section{Methods}

\section{Study design and sample collection}

The cross-sectional study 'Portuguese Population's Food Habits and Lifestyles' was designed and promoted by the Portuguese Society of Nutrition and Food Sciences with the support of Nestlé, within a protocol of scientific sponsorship between both institutions ${ }^{(7,22)}$. Data collection was conducted from February to April 2009. A representative sample of 3529 Portuguese adults (aged 18-93 years old; $52.2 \%$ women) was studied. The sample size used in the analyses varies because of incompleteness of some data. A questionnaire was developed specifically for this study, and anthropometric measurements (height, weight and waist circumference (WC)) were collected. All participants were interviewed and measured individually at home by well-trained interviewers.

The participants were from the seven Portuguese regions according to NUTS II (the Nomenclature of Territorial Units for
Statistics), including the two autonomous regions: Madeira and Azores. The sample was selected using random route method. To ensure national representativeness, quota sampling by sex and age groups was used, and results were weighted on the basis of region of residence, in accordance with the National Census 2001. In this paper, we present the results from only part of the larger study, from which overall methodological aspects were described in previous publications ${ }^{(7,22)}$.

\section{Anthropometric measurements and body weight status as outcomes}

Height, weight and WC were measured according to standardised procedures, respectively, to the nearest $0.01 \mathrm{~m}, 0 \cdot 1 \mathrm{~kg}$ and $0.1 \mathrm{~cm}$. Participants were asked to remove their shoes, heavy clothes or hats. Height and weight were measured by keeping the respondent with head in Frankfort horizontal plane position, shoulders relaxed, arms at both sides, legs straight and feet close together. Body weight was measured by subtracting the estimated weight of the remaining clothing. WC was measured at the midaxillary line, between the last rib and the iliac crest ${ }^{(8,12)}$.

General adiposity was assessed by BMI and abdominal adiposity by WHtR. BMI $\left(\mathrm{kg} / \mathrm{m}^{2}\right)$ was calculated as weight $(\mathrm{kg}) /$ height $(\mathrm{m})^{2}$. Participants were classified into four categories: underweight $\left(\mathrm{BMI}<18.5 \mathrm{~kg} / \mathrm{m}^{2}\right)$, normal weight $\left(18.5 \leq \mathrm{BMI}<25.0 \mathrm{~kg} / \mathrm{m}^{2}\right)$, overweight $\quad(25.0 \leq \mathrm{BMI}<30.0 \mathrm{~kg} /$ $\left.\mathrm{m}^{2}\right)$ and obesity $\left(\mathrm{BMI} \geq 30 \cdot 0 \mathrm{~kg} / \mathrm{m}^{2}\right)^{(8)}$. For subsequent analyses, overweight and obesity were combined into one category called 'high general adiposity' and compared with normal weight called 'normal general adiposity'. The WHtR was calculated as WC $(\mathrm{cm}) /$ height $(\mathrm{cm})$. Respondents were classified into two categories: 'normal abdominal adiposity' (WHtR <0.5) and 'high abdominal adiposity' (WHtR $\geq 0 \cdot 5)^{(13)}$.

To analyse the dependency between BMI and WHtR in assessing adiposity, all respondents were first classified into four categories, which were then combined into two main categories (1) overall compatible classification by both indexes: (i) respondents having normal general adiposity $\left(18.5 \leq \mathrm{BMI}<25.0 \mathrm{~kg} / \mathrm{m}^{2}\right)$ and normal abdominal adiposity (WHtR $<0.5$ ), and (ii) respondents having high general adiposity $\left(\mathrm{BMI} \geq 25.0 \mathrm{~kg} / \mathrm{m}^{2}\right)$ and high abdominal adiposity (WHtR $\geq 0.5$ ); (2) overall incompatible classification by both indexes: (i) respondents having high general adiposity $\left(\mathrm{BMI} \geq 25 \cdot 0 \mathrm{~kg} / \mathrm{m}^{2}\right.$ ) and normal abdominal adiposity (WHtR $<0.5$ ), and (ii) respondents having normal general adiposity $\left(18.5 \leq \mathrm{BMI}<25.0 \mathrm{~kg} / \mathrm{m}^{2}\right)$ and high abdominal adiposity (WHtR $\geq 0 \cdot 5$ ).

\section{Socio-demographic factors as explanatory variables}

The participants were asked about their age (in completed years, and then categorised into four groups: 18-29, 30-44, 45-64 and 65 years or more) and the number of completed education years (grouped according to the national education levels into six groups: below fourth grade, fourth grade, sixth grade, ninth grade, twelfth grade and bachelor/university education). Some other socio-demographic factors were also evaluated: sex (male, female), occupational status (active, student, unemployed, housewife/ househusband, retired), marital status (married/equivalent, single, 
separated/divorced, widowed) and region of residence (North, Centre, Lisbon and Tagus Valley (LTV), Alentejo, Algarve, Madeira, Azores).

\section{Energy intake and lifestyle factors as confounders}

Energy intake data were collected using a single 24-h dietary recall method (1 weekday) and expressed in $\mathrm{kJ} / \mathrm{d}$ (kcal/d). Physical activity was estimated based on the Metabolic Equivalent of Task (MET) and expressed in MET-min/week. The short version of International Physical Activity Questionnaire (IPAQ) was used ${ }^{(23)}$. Smoking status was evaluated using a three-option standard question: never smoker, former smoker and current smoker.

\section{Statistical analysis}

Statistical analysis was performed using IBM SPSS Statistics for Windows, version 21.0 (IBM SPSS Inc.). Differences were considered statistically significant when $P<0 \cdot 05$. Mean values were compared using independent samples $t$ test and one-way ANOVA. Mean ranks were compared using Mann-Whitney and Kruskal-Wallis tests. The percentage distribution of sociodemographic factors, BMI and WHtR classification and dependency between both measures in assessing adiposity were compared by sex using $\chi^{2}$ test and Fisher's exact test. The influence of socio-demographic factors on prevalence and dependency in risk classification of general and abdominal adiposity was assessed using the following: (i) comparison of percentage distribution by $\chi^{2}$ test and Fisher's exact test, and (ii) application of binary logistic regression analysis to calculate $\mathrm{OR}$. The dependent variables were general and abdominal adiposity and dependency in adiposity classification between BMI and WHtR (all as categorical variables). The independent variables were six socio-demographic factors (as categorical variables) and three anthropometric measures (height, weight and waist as continuous variables), which were tested only for overall incompatible classification by BMI and WHtR. Both crude and adjusted OR were computed. OR adjustment was made for all other analysed socio-demographic factors, and additionally for energy intake, physical activity and smoking status as possible confounders. The reference groups $(\mathrm{OR}=1.00)$ for dependent variables were as follows: normal general adiposity $\left(18.5 \leq \mathrm{BMI}<25.0 \mathrm{~kg} / \mathrm{m}^{2}\right)$, normal abdominal adiposity (WHtR $<0.5$ ) and overall compatible classification by BMI and WHtR $\left(18.5 \leq \mathrm{BMI}<25.0 \mathrm{~kg} / \mathrm{m}^{2}\right.$ and $\mathrm{WHtR}<0.5$, or $\mathrm{BMI} \geq 25.0 \mathrm{~kg} / \mathrm{m}^{2}$ and $\mathrm{WHtR} \geq 0.5$ ). The $95 \%$ CI were calculated, and Wald's test was used for comparison of the OR.

\section{Results}

\section{Socio-demographic factors and anthropometric measures}

Table 1 shows the socio-demographic and anthropometric characteristics of the total sample and by sex. Some of these epidemiological results were described in a previous publication from the project $^{(7)}$ and are presented again for sample characterisation. In Portuguese adults, mean BMI was $25.4 \mathrm{~kg} / \mathrm{m}^{2}$ and mean WHtR was 0.50. Mean values of both measures were higher in men than in women (BMI: $26 \cdot 3 \mathrm{~kg} / \mathrm{m}^{2} v$. $24.6 \mathrm{~kg} / \mathrm{m}^{2}$, WHtR: 0.52 v. 0.48 , respectively).

\section{Influence of socio-demographic factors on general and} abdominal adiposity

Significant influence of all tested socio-demographic factors was observed (Tables 2 and 3). High general adiposity and high abdominal adiposity were more frequent in men than in women, and in older age groups than in younger age groups (Tables 1 and 2). There was an inverse association between education level and high general adiposity, as well as high abdominal adiposity (Table 2 ). With regard to occupational and marital status, the lowest prevalence of high general adiposity and high abdominal adiposity was observed in students and in singles, whereas the highest prevalence was in retired and widowed respondents. Considering the region of residence, high general adiposity prevalence was the highest in Azores and Madeira and the lowest in Algarve, whereas high abdominal adiposity prevalence was the highest in Madeira, Alentejo and Azores, and the lowest in North and LTV.

These results were confirmed in binary logistic regression analysis (Table 3). In general, adjusted OR of high general adiposity and/or high abdominal adiposity were significantly higher for male respondents, all age groups ( $\geq 65$ years: only high abdominal adiposity), all education levels (twelfth grade: only high general adiposity), five regions of residence (Alentejo, Algarve: only high abdominal adiposity); on the contrary, OR were significantly lower for students, unemployed respondents (only high abdominal adiposity) and singles (only high abdominal adiposity). After adjustment, the overall influence of marital status on high general adiposity and high abdominal adiposity was no longer significant.

The influence of socio-demographic factors on general and abdominal adiposity by sex was similar to the above results (data not shown).

\section{Dependency between BMI and waist:height ratio in assessing adiposity}

The proportion of overall compatible classification by BMI and WHtR in the total sample was $76.0 \%$ (Table 2); $40.9 \%$ of the respondents had normal general adiposity and normal abdominal adiposity, and $35 \cdot 1 \%$ had high general adiposity and high abdominal adiposity. The overall incompatible classification in the total sample was $24.0 \%$ (Table 2 ); $7.6 \%$ were classified as normal weight by BMI but as high abdominal adiposity by WHtR, and $16.4 \%$ were classified as high general adiposity by BMI but as normal abdominal adiposity by WHtR. On the basis of percentage distribution, all tested socio-demographic factors, except region of residence, significantly influenced the compatibility classification between both measures (Table 2). However, the adjusted OR of incompatible classification was significant only for sex and education level (Table 3). The proportion of incompatible classification was higher in men than in women $(26.5$ v. $21.8 \% ; P=0.0015$; Table 2), and adjusted OR for men compared with women was 1.64 $(P<0.0001$; Table 3$)$. The highest percentage of incompatibly classified respondents was for fourth grade of education $(32.8 \%)$ and the lowest for twelfth grade (19.7\%) (Table 2), and adjusted OR for fourth grade of education compared with 
Table 1. Socio-demographic factors and anthropometric measures in total sample and by sex groups in Portuguese adults (\%) - the study 'Portuguese Population's Food Habits and Lifestyles' (2009)

(Mean values and standard deviations; or percentages)

\begin{tabular}{|c|c|c|c|c|c|c|c|}
\hline \multirow[b]{3}{*}{ Socio-demographic factors and anthropometric measures } & & & \multicolumn{4}{|c|}{ Sex } & \multirow[b]{3}{*}{$P$} \\
\hline & \multicolumn{2}{|c|}{ Total ( $n$ 3529) } & \multicolumn{2}{|c|}{ Men $(n$ 1687) } & \multicolumn{2}{|c|}{ Women ( $n$ 1842) } & \\
\hline & Mean & SD & Mean & SD & Mean & SD & \\
\hline \multicolumn{8}{|l|}{ Sex $(\%)$} \\
\hline Male & \multicolumn{2}{|c|}{$47 \cdot 8$} & \multicolumn{2}{|c|}{-} & \multicolumn{2}{|c|}{-} & \\
\hline Female & \multicolumn{2}{|c|}{$52 \cdot 2$} & \multicolumn{2}{|c|}{-} & \multicolumn{2}{|c|}{-} & \\
\hline Age (years) ${ }^{*} \dagger$ & $45 \cdot 2$ & 18.5 & 44.4 & $18 \cdot 4$ & $46 \cdot 0$ & 18.6 & 0.0103 \\
\hline \multicolumn{8}{|l|}{ Age (years) (\%) } \\
\hline $18-29$ & \multirow{2}{*}{\multicolumn{2}{|c|}{$27 \cdot 4$}} & \multirow{2}{*}{\multicolumn{2}{|c|}{$29 \cdot 1$}} & \multicolumn{2}{|c|}{$25 \cdot 7$} & 0.0065 \\
\hline $30-44$ & \multirow{2}{*}{\multicolumn{2}{|c|}{$22 \cdot 4$}} & & \multirow{2}{*}{$21 \cdot 8$} & & & \\
\hline $45-64$ & & & & & & & \\
\hline$\geq 65$ & & & & & & & \\
\hline Education (years) ${ }^{*} \dagger$ & $9 \cdot 3$ & 3.8 & 9.4 & 3.5 & 9.2 & $4 \cdot 0$ & 0.0327 \\
\hline Education level (completed grade) (\%) & & & & & & & \\
\hline$<4$ th & & & & & & & $<0.0001$ \\
\hline 4th & & & & & & & \\
\hline 6th & & & & & & & \\
\hline 9th & & & & & & & \\
\hline 12th & & & & & & & \\
\hline Bachelor/university & & & & & & & \\
\hline Occupational status (\%) & & & & & & & \\
\hline Active & & & & & & & $<0.0001$ \\
\hline Student & & & & & & & \\
\hline Unemployed & & & & & & & \\
\hline Housewife/househusband & & & & & & & \\
\hline Retired & & & & & & & \\
\hline Marital status (\%) & & & & & & & \\
\hline Married/equivalent & & & & & & & $<0.0001$ \\
\hline Single & & & & & & & \\
\hline Separated/divorced & & & & & & & \\
\hline Widowed & & & & & & & \\
\hline Region of residence (\%) & & & & & & & \\
\hline North & & & & & & & 0.9952 \\
\hline Centre & & & & & & & \\
\hline LTV & & & & & & & \\
\hline Alentejo & & & & & & & \\
\hline Algarve & & & & & & & \\
\hline Madeira & & & & & & & \\
\hline Azores & & & & & & & \\
\hline Height $(m)^{*} \dagger$ & 1.69 & 0.08 & 1.74 & 0.07 & 1.64 & 0.07 & $<0.0001$ \\
\hline Weight $(\mathrm{kg})^{\star} \dagger$ & $72 \cdot 1$ & $12 \cdot 5$ & $79 \cdot 3$ & $10 \cdot 3$ & $65 \cdot 6$ & 10.5 & $<0.0001$ \\
\hline Waist circumference $(\mathrm{cm})^{\star} \ddagger$ & $84 \cdot 0$ & 13.4 & 89.4 & 11.6 & 78.9 & $13 \cdot 0$ & $<0.0001$ \\
\hline BMI $\left(\mathrm{kg} / \mathrm{m}^{2}\right)^{*} \ddagger$ & $25 \cdot 4$ & 4.0 & $26 \cdot 3$ & 3.2 & 24.6 & 4.4 & $<0.0001$ \\
\hline WHtR ${ }^{\star} \ddagger$ & 0.50 & 0.08 & 0.52 & 0.07 & 0.48 & 0.09 & $<0.0001$ \\
\hline BMI classification (\%) & & & & & & & \\
\hline Underweight $\left(<18.5 \mathrm{~kg} / \mathrm{m}^{2}\right)$ & & & & & & & $<0.0001$ \\
\hline Normal weight $\left(18.5-24.9 \mathrm{~kg} / \mathrm{m}^{2}\right)$ & & & & & & & \\
\hline Overweight $\left(25.0-29.9 \mathrm{~kg} / \mathrm{m}^{2}\right)$ & & & & & & & \\
\hline Obesity $\left(\geq 30.0 \mathrm{~kg} / \mathrm{m}^{2}\right)$ & & & & & & & \\
\hline WHtR classification (\%) & & & & & & & \\
\hline Normal abdominal adiposity $(<0.5)$ & & & & & & & $<0.0001$ \\
\hline High abdominal adiposity $(\geq 0.5)$ & & & & & & & \\
\hline
\end{tabular}

$n$, Sample size; LTV, Lisbon and Tagus Valley; WHtR, waist:height ratio.

* $P$ value - significance level of the following tests: $x^{2}$ test and Fisher's exact test for percentage distributions.

t Independent samples $t$ test and one-way ANOVA for mean values of parametric variables.

$\ddagger$ Mann-Whitney test and Kruskal-Wallis test for mean values of non-parametric variables.

bachelor/university education level was $1.84 \quad(P<0 \cdot 001$; Table 3). In incompatibly classified respondents, adjusted OR were slightly but significantly higher for weight and lower for WC $(P<0 \cdot 0001$; Table 3$)$.

\section{Discussion}

It was found that above half of the Portuguese adults were overweight or obese, and $>40 \%$ had high abdominal adiposity, which indicates a serious public health problem. Similar results were obtained for other European countries ${ }^{(3,20)}$. High general adiposity and high abdominal adiposity prevalence was higher in men and in older participants, which has been widely confirmed by other authors ${ }^{(4,21,24)}$. Another study among Portuguese adults also found a higher prevalence of overall overweight in men aged 18-64 years, but in the elderly ( $\geq 65$ years) the rate was higher in women. In the same study, abdominal adiposity prevalence was higher in women, regardless of age ${ }^{(19)}$. 
Table 2. Prevalence and dependency in the classification of general and abdominal adiposity by socio-demographic factors in Portuguese adults (\%) - the study 'Portuguese Population's Food Habits and Lifestyles' (2009)

\begin{tabular}{|c|c|c|c|c|c|c|c|c|c|}
\hline \multirow[b]{3}{*}{ Socio-demographic factors } & \multicolumn{3}{|c|}{ BMI (general adiposity ${ }^{\star}$ ) } & \multicolumn{3}{|c|}{ WHtR (abdominal adiposity†) } & \multicolumn{3}{|c|}{ Classification by BMl and WHtR $\ddagger$} \\
\hline & $\begin{array}{l}\text { Normal } \\
\text { (n 1658) }\end{array}$ & $\begin{array}{c}\text { High } \\
(n 1763)\end{array}$ & \multirow[b]{2}{*}{$P$} & $\begin{array}{l}\text { Normal } \\
\text { (n 2003) }\end{array}$ & $\begin{array}{c}\text { High } \\
(n 1454)\end{array}$ & \multirow[b]{2}{*}{$P$} & $\begin{array}{c}\text { Compatible } \\
\text { (n 2580) }\end{array}$ & $\begin{array}{l}\text { Incompatible } \\
\text { (n 817) }\end{array}$ & \multirow[b]{2}{*}{$P$} \\
\hline & Mean & SD & & Mean & SD & & Mean & $\mathrm{SD}$ & \\
\hline Total sample & $47 \cdot 7$ & $50 \cdot 8$ & & $57 \cdot 9$ & $42 \cdot 1$ & & $76 \cdot 0$ & $24 \cdot 0$ & \\
\hline \multicolumn{10}{|l|}{ Sex } \\
\hline Female & $59 \cdot 2$ & $38 \cdot 2$ & \multirow[t]{2}{*}{$<0.0001$} & $69 \cdot 4$ & $30 \cdot 6$ & \multirow[t]{2}{*}{$<0.0001$} & $78 \cdot 2$ & $21 \cdot 8$ & \multirow[t]{2}{*}{0.0015} \\
\hline Male & $35 \cdot 2$ & 64.5 & & $45 \cdot 5$ & 54.5 & & 73.5 & $26 \cdot 5$ & \\
\hline \multicolumn{10}{|l|}{ Age (years) } \\
\hline $18-29$ & $68 \cdot 3$ & $27 \cdot 4$ & \multirow[t]{4}{*}{$<0.0001$} & 83.5 & $16 \cdot 5$ & \multirow[t]{4}{*}{$<0.0001$} & $79 \cdot 7$ & $20 \cdot 3$ & \multirow[t]{4}{*}{0.0114} \\
\hline $30-44$ & $50 \cdot 9$ & $48 \cdot 6$ & & $64 \cdot 3$ & $35 \cdot 7$ & & $76 \cdot 2$ & 23.8 & \\
\hline $45-64$ & $36 \cdot 2$ & 63.0 & & $42 \cdot 3$ & $57 \cdot 7$ & & $74 \cdot 1$ & $25 \cdot 9$ & \\
\hline$\geq 65$ & 33.7 & $66 \cdot 3$ & & $39 \cdot 8$ & $60 \cdot 2$ & & $73 \cdot 6$ & $26 \cdot 4$ & \\
\hline \multicolumn{10}{|c|}{ Education level (completed grade) } \\
\hline$<4$ th & $26 \cdot 6$ & $73 \cdot 4$ & \multirow{6}{*}{$<0.0001$} & $30 \cdot 8$ & $69 \cdot 2$ & \multirow{6}{*}{$<0.0001$} & $74 \cdot 2$ & $25 \cdot 8$ & \multirow{6}{*}{$<0.0001$} \\
\hline 4th & $28 \cdot 2$ & 71.8 & & $37 \cdot 9$ & $62 \cdot 1$ & & $67 \cdot 2$ & $32 \cdot 8$ & \\
\hline 6 th & $26 \cdot 0$ & 74.0 & & $31 \cdot 8$ & $68 \cdot 2$ & & 77.5 & 22.5 & \\
\hline 9th & $43 \cdot 7$ & $55 \cdot 1$ & & $56 \cdot 2$ & $43 \cdot 8$ & & $76 \cdot 2$ & $23 \cdot 8$ & \\
\hline 12th & $64 \cdot 0$ & $33 \cdot 8$ & & $76 \cdot 8$ & $23 \cdot 2$ & & $80 \cdot 3$ & $19 \cdot 7$ & \\
\hline Bachelor/university & $61 \cdot 5$ & $35 \cdot 5$ & & $69 \cdot 3$ & $30 \cdot 7$ & & $77 \cdot 0$ & 23.0 & \\
\hline \multicolumn{10}{|l|}{ Occupational status } \\
\hline Active & $45 \cdot 7$ & $53 \cdot 0$ & \multirow[t]{5}{*}{$<0.0001$} & $56 \cdot 0$ & $44 \cdot 0$ & \multirow{5}{*}{$<0.0001$} & $75 \cdot 1$ & 24.9 & \multirow{5}{*}{0.0043} \\
\hline Student & $76 \cdot 2$ & $19 \cdot 1$ & & 88.7 & $11 \cdot 3$ & & $82 \cdot 8$ & $17 \cdot 2$ & \\
\hline Unemployed & $52 \cdot 7$ & $45 \cdot 2$ & & 71.5 & $28 \cdot 5$ & & $76 \cdot 9$ & $23 \cdot 1$ & \\
\hline Housewife/househusband & $50 \cdot 0$ & $50 \cdot 0$ & & $57 \cdot 9$ & $42 \cdot 1$ & & $73 \cdot 4$ & $26 \cdot 6$ & \\
\hline Retired & $30 \cdot 8$ & $69 \cdot 2$ & & $36 \cdot 3$ & 63.7 & & $74 \cdot 1$ & $25 \cdot 9$ & \\
\hline \multicolumn{10}{|l|}{ Marital status } \\
\hline Married/equivalent & $39 \cdot 7$ & $59 \cdot 9$ & \multirow[t]{4}{*}{$<0.0001$} & $47 \cdot 6$ & $52 \cdot 4$ & $<0.0001$ & 74.4 & $25 \cdot 6$ & 0.0258 \\
\hline Single & $65 \cdot 1$ & $31 \cdot 2$ & & $80 \cdot 1$ & $19 \cdot 9$ & & $79 \cdot 2$ & $20 \cdot 8$ & \\
\hline Separated/divorced & 44.5 & $53 \cdot 9$ & & $55 \cdot 7$ & $44 \cdot 3$ & & $75 \cdot 7$ & $24 \cdot 3$ & \\
\hline Widowed & $37 \cdot 5$ & $62 \cdot 5$ & & $43 \cdot 9$ & $56 \cdot 1$ & & $73 \cdot 7$ & $26 \cdot 3$ & \\
\hline Region of residence & & & & & & & & & \\
\hline North & $49 \cdot 6$ & $49 \cdot 2$ & 0.0022 & $62 \cdot 3$ & $37 \cdot 7$ & $<0.0001$ & 73.9 & $26 \cdot 1$ & 0.2300 \\
\hline Centre & $48 \cdot 6$ & 49.9 & & $55 \cdot 3$ & $44 \cdot 7$ & & 75.5 & 24.5 & \\
\hline LTV & 47.4 & 50.5 & & $60 \cdot 6$ & 39.4 & & 77.4 & $22 \cdot 6$ & \\
\hline Alentejo & 41.4 & 57.5 & & 39.2 & $60 \cdot 8$ & & 74.7 & $25 \cdot 3$ & \\
\hline Algarve & 53.5 & $45 \cdot 7$ & & 53.5 & $46 \cdot 5$ & & $81 \cdot 1$ & 18.9 & \\
\hline Madeira & $39 \cdot 0$ & $59 \cdot 7$ & & $37 \cdot 7$ & $62 \cdot 3$ & & $81 \cdot 6$ & 18.4 & \\
\hline Azores & $27 \cdot 8$ & $70 \cdot 8$ & & $40 \cdot 8$ & $59 \cdot 2$ & & $80 \cdot 0$ & $20 \cdot 0$ & \\
\hline
\end{tabular}

n, Sample size; LTV, Lisbon and Tagus Valley; WHtR, waist:height ratio.

* General adiposity: normal $\left(18.5 \leq \mathrm{BMl}<25.0 \mathrm{~kg} / \mathrm{m}^{2}\right)$, high $\left(\mathrm{BMl} \geq 25.0 \mathrm{~kg} / \mathrm{m}^{2}\right)$.

$\dagger$ Abdominal adiposity: normal (WHtR $<0.5)$, high (WHtR $\geq 0.5)$.

$\ddagger$ Classification by BMl and WHtR: incompatible (BMI $\geq 25.0 \mathrm{~kg} / \mathrm{m}^{2}$ and $\mathrm{WHtR}<0.5 ; 18.5 \leq \mathrm{BMl}<25.0 \mathrm{~kg} / \mathrm{m}^{2}$ and $\left.\mathrm{WHtR} \geq 0.5\right)$, compatible $\left(18.5 \leq \mathrm{BMl}<25.0 \mathrm{~kg} / \mathrm{m}^{2}\right.$ and $\mathrm{WHtR}<0.5$; $\mathrm{BMI} \geq 25.0 \mathrm{~kg} / \mathrm{m}^{2}$ and $\left.\mathrm{WHtR} \geq 0.5\right) ; P$ value - significance level of $X^{2}$ test.

Geographic variation in obesity prevalence is observed between European countries ${ }^{(2,3,20)}$, as well as within regions of each country, especially in southern European countries ${ }^{(9,25)}$. Higher prevalence of overweight was found in southern countries than in northern countries. This study showed the highest prevalence of general adiposity in the islands of Azores and Madeira, and the lowest in the south of the country (Algarve). Abdominal adiposity rates were the highest in Azores, Madeira and Alentejo, and the lowest in the North and the capital area (LTV). A study among Spanish children and adolescents demonstrated a higher prevalence of overweight in the Canary Islands (similarly to the Portuguese results) and southern regions (in contrast to the presented results) ${ }^{(9)}$. Region of residence is associated with inhabitants' SES, their affluence and education level, which have been inversely associated with obesity ${ }^{(6,9)}$. However, the obtained results can only be partially explained by wealth (Gross Domestic Product (GDP) per capita in 2011) of Portuguese regions: North, Alentejo and Azores were relatively poor, whereas LTV, Madeira and Algarve were the richest ones $^{(26)}$.

After adjustment for other socio-demographic and lifestyle factors, the overall influence of all tested socio-demographic factors on general and abdominal adiposity remained significant, except for marital status. However, after adjustment for confounders, singles, compared with married ones, presented about $30 \%$ lower risk of abdominal adiposity prevalence. Other studies confirmed that singles are slimmer than married participants, regardless of $\operatorname{sex}^{(4)}$. In the past years, an increase in women's employment and a reduction in time for preparing and sharing meals with family contributed to a higher eating out frequency, mostly in popular and relatively cheap fast-foods, and lowered diet quality ${ }^{(6)}$.

This study showed a lower risk of general and abdominal adiposity in students and the opposite in retired participants, but after adjustment for confounders (including age) the results were significant only for students. It can be related to the strong 
influence of age as an obesity risk factor, especially in older people, and a possible influence of other than the investigated lifestyle factors. A significant increase in general and abdominal adiposity prevalence with age has been confirmed in several studies $^{(4,21,24)}$. However, after adjustment for socio-demographic and lifestyle factors, the highest risk of general and abdominal adiposity was observed in middle-aged individuals (45-64 years). A similar association with age (maximum for 50-59 years) and significant influence of occupational status on overweight were previously observed among Portuguese adults ${ }^{(4)}$. The decreasing general and abdominal adiposity prevalence in elderly can be explained by changes in dietary habits because of lower appetite, perception of flavours, chewing problems and decreased eating pleasure, as well as loneliness (widowed) and lower motivation to prepare meals ${ }^{(27,28)}$.

An inverse relationship between education level and general and abdominal adiposity was found. After adjustment for confounders, the risk of general and abdominal adiposity was, respectively, above eight times and almost seven times higher among adults with the lowest education level (compared with the highest educated ones). Similar results were also reported in previous research conducted in Portugal ${ }^{(4,19,21)}$ and in other European countries $^{(6,11,17,21)}$. However, larger educational inequalities in overweight were observed in women from southern European countries, especially Portugal ${ }^{(17)}$. Low education has been associated with lower occupational status, lower incomes and poor nutritional and health knowledge, which contributes to obesity.

The compatible classification in assessing adiposity by BMI and WHtR accounted for about three-fourths of the total sample, being similar in different sex and age groups (data not shown). Only few respondents (7.6\%) had high adiposity according to WHtR but not according to BMI, and about one-sixth of respondents (16.4\%) were classified as high adiposity by BMI but not by WHtR. The latter respondents could have early general overweight, but not abdominal obesity yet. On the other hand, they could be more active, have higher muscle mass and weigh more. It was found that incompatibly classified respondents had significantly higher weight and lower WC. BMI is a commonly used indicator of general adiposity, but it does not take into account body fat distribution or muscle mass variations between individuals ${ }^{(8,12)}$. Compared with the percentage of body fat assessed by skinfolds, BMI overestimated body fat in lean respondents (sedentary and active men, active women), but underestimated it in obese ones (sedentary women) ${ }^{(29)}$. In the present study, higher incompatibility in assessing adiposity by BMI and WHtR was found in men than in women. Commonly used cut-off points of both indexes are not specified by sex. Second, men generally have higher muscle mass than women ${ }^{(12)}$. Differences in assessing adiposity using BMI and other anthropometric measures by sex, age and ethnic groups have been demonstrated by several authors ${ }^{(13,29)}$. Some differences between BMI and WHtR were found not only in adiposity assessment but also in predicting disease and mortality risk ${ }^{(30)}$. Many studies confirmed that WHtR is a better predictor of CVD, diabetes, the metabolic syndrome and mortality risk compared with BMI, but also compared with other indicators of abdominal adiposity (e.g. WC, WHtR) ${ }^{(13,14)}$. A systematic review showed that the association with all-cause mortality was U- or J-shaped for BMI and $\mathrm{WC}$, but it was positive for $\mathrm{WHtR}$ and $\mathrm{WHR}^{(30)}$
These research data were collected in 2009 among a representative sample, providing new epidemiological data for Portuguese adults compared with previous studies ${ }^{(4,18,19)}$. The main strengths of this study are including not only the mainland Portugal but also the autonomous regions of the country (islands), and using WHtR to assess abdominal adiposity. In previous studies, only mainland regions of Portugal were considered and WC was used to assess abdominal adiposity ${ }^{(4,18,19)}$. The WHtR is a better indicator of abdominal adiposity than WC, in which cut-off points do not take into account differences in respondents' height ${ }^{(13)}$. Several researchers focused on the influence of sociodemographic factors on overweight assessed by $\mathrm{BMI}^{(9-11,15-17)}$, but only a few studies used WHtR as an indicator of abdominal obesity $^{(20)}$. To our best knowledge, there are no large and comprehensive studies regarding the influence of sociodemographic factors on dependency in classification of general and abdominal obesity. Height, weight and waist were measured, not self-reported, which is a more accurate assessment procedure that also strengths the data ${ }^{(12,19)}$. This study involved adults aged 18-93 years, whereas some previous studies included only Portuguese $<65$ years $^{(4,18)}$.

The limitations of this study are related to the questionnaire with self-reported questions, which might have introduced some recall bias ${ }^{(12,24)}$. Similarly, physical activity assessed by the IPAQ might be overestimated, and energy intake assessed by a single 24-h recall is possibly underestimated, because of social desirability bias ${ }^{(12)}$. Although according to guidance on the EU (European Union) Menu(31) the methodology for assessing population energy and nutrient intake in adults should include at least two 24-h recalls in non-consecutive days, this is a large sample study and only a single 24-h recall was affordable. However, there is also some evidence from other populations that report similar ability of single and triple $24-\mathrm{h}$ recall in dietary assessment ${ }^{(32)}$. The present study did not include other possible confounders (e.g. genes, neighbourhood or income) that were important for overweight prevalence ${ }^{(5,16)}$. Dependency between BMI and WHtR in assessing adiposity was tested, but both indexes have not been compared with a better method to assess body fatness (e.g. bioelectrical impedance analysis or skinfolds $)^{(12)}$. In this population, comparison of BMI and WHtR in predicting disease and mortality risk was not tested, but it is an important issue to investigate in future research.

\section{Conclusions}

In conclusion, the BMI- and WHtR-incompatible adiposity classification was significantly higher in men and in low-educated individuals, meaning that in these groups application of both adiposity measures is limited. Although the WHtR takes into account the adiposity distribution and may be a better indicator in risk classification than BMI, especially among more physically active people having higher muscle mass, research on improving indicators for assessing adiposity is necessary. Future surveys should focus on developing at least sex-specific cut-off points for both indexes. Until then, both BMI and WHtR should be used for comprehensive assessment of high adiposity levels.

The observed high prevalence of general and abdominal adiposity poses huge concern for the current and future health of the 
Portuguese population. All socio-demographic factors significantly predicted the prevalence of general and abdominal adiposity in Portuguese adults. The implementation of more effective strategies for preventing and reducing high adiposity levels and its health consequences at the national level is necessary. Such plans should be directed primarily to men, older, low-educated ones, living in the islands and in poor regions of the country.

\section{Acknowledgements}

The authors thank the participants for their contributions to the study.

The study was designed and promoted by the Portuguese Society of Nutrition and Food Sciences with the financial support of Nestlé, within a protocol of scientific sponsorship between both institutions.

M. D. V. d. A., F. C., C. A. and B. F. were responsible for the conception, design and data collection of the main study. J. K., R. P. and S. R. were responsible for the design, analysis and interpretation of data for this particular paper. S. P. was responsible for the calculation and data cleaning of the daily energy intake variable. J. K., R. P. and S. R. were responsible for writing the manuscript. R. P. and S. R. were responsible for revising the manuscript critically for important intellectual content. The manuscript has been revised by all co-authors.

There are no conflicts of interest.

\section{References}

1. World Health Organization (2011) Global Status Report on Noncommunicable Diseases 2010. Geneva: WHO.

2. Berghöfer A, Pischon T, Reinhold T, et al. (2008) Obesity prevalence from a European perspective: a systematic review. BMC Public Health 8, 1-10.

3. Elmadfa I, et al. (2009) European Nutrition and Health Report 2009. Forum Nutr 62, 1-405.

4. Carmo I, Santos O, Camolas J, et al. (2008) Overweight and obesity in Portugal: national prevalence in 2003-2005. Obe $\operatorname{Rev}$ 9, 11-19.

5. Organization for Economic Co-Operation and Development (2012) Health at a Glance: Europe 2012. Paris: OECD Publishing.

6. World Health Organization (2014) Review of Social Determinants and the Health Divide in the WHO European Region: Final Report. Copenhagen: WHO.

7. Pó́nhos R, Franchini B, Afonso C, et al. (2009) Alimentação e estilos de vida da população portuguesa (Portuguese population's food habits and lifestyles). Alim Hum 15, 43-60 (English abstract).

8. World Health Organization (1998) Obesity: preventing and managing the global epidemic. Report of a WHO Consultation on Obesity. Geneva: WHO

9. Serra-Majem L, Bartrina JA, Pérez-Rodrigo C, et al. (2006) Prevalence and determinants of obesity in Spanish children and young people. BrJ Nutr 96, Suppl. 1, S67-S72.

10. Ball K \& Crawford D (2005) Socioeconomic status and weight change in adults: a review. Soc Sci Med 60, 1987-2010.

11. McLaren L (2007) Socioeconomic status and obesity. Epidemiol Rev 29, 29-48.

12. Gibson RS (2005) Principles of Nutritional Assessment, 2nd ed. New York: Oxford University Press.

13. Ashwell M, Gunn P \& Gibson S (2012) Waist-to-height ratio is a better screening tool than waist circumference and BMI for adult cardiometabolic risk factors: systematic review and meta-analysis. Obes Rev 13, 275-286.

14. Schneider HJ, Friedrich N, Klotsche J, et al. (2010) The predictive value of different measures of obesity for incident cardiovascular events and mortality. J Clin Endocrinol Metab 95, 1777-1785.

15. Ball K, Mishra G \& Crawford D (2002) Which aspects of socioeconomic status are related to obesity among men and women? Int J Obes 26, 559-565.

16. Crawford DA, Ball K, Cleland VJ, et al. (2012) Home and neighbourhood correlates of BMI among children living in socioeconomically disadvantaged neighbourhoods. Br J Nutr 107, 1028-1036.

17. Roskam A-JR, Kunst AE, Van Oyen H, et al. (2010) Comparative appraisal of educational inequalities in overweight and obesity among adults in 19 European countries. Int J Epidemiol 39, 392-404.

18. Carmo I, Santos O, Camolas J, et al. (2006) Prevalence of obesity in Portugal. Obes Rev 7, 233-237.

19. Sardinha LB, Santos DA, Silva AM, et al. (2012) Prevalence of overweight, obesity, and abdominal obesity in a representative sample of Portuguese adults. PLOS ONE 7, 1-8.

20. Rodríguez-Rodríguez E, López-Plaza B, López-Sobaler AM, et al. (2011) Prevalencia de sobrepeso y obesidad en adultos espańoles (Overweight and obesity among Spanish adults). Nutr Hosp 26, 355-363.

21. Stewart-Knox B, Duffy ME, Bunting B, et al. (2012) Associations between obesity (BMI and waist circumference) and sociodemographic factors, physical activity, dietary habits, life events, resilience, mood, perceived stress and hopelessness in healthy older Europeans. BMC Public Health 12, 424-435.

22. Poínhos R, Correia F, Durão C, et al. (2011) Determinants of weight and health status perception among Portuguese adults. Alim Hum 17, 7-14.

23. Craig CL, Marshall AL, Sjöström M, et al. (2003) International physical activity questionnaire: 12-country reliability and validity. Med Sci Sports Exerc 35, 1381-1395.

24. Wang H, Wang J, Liu M-M, et al. (2012) Epidemiology of general obesity, abdominal obesity and related risk factors in urban adults from 33 communities of northeast china: the CHPSNE study. BMC Public Health 12, 967-976.

25. Turchetta F, Gatto G, Saulle R, et al. (2012) Systematic review and meta-analysis of the prevalence of overweight and obesity among school-age children in Italy. Epidemiol Prev 36, 188-195.

26. Eurostat (2014) GDP per capita in the EU in 2011: seven capital regions among the ten most prosperous, European Commission, STAT/14/29. https://www.destatis.de/Europa/EN/Service/Media/ Pressreleases/GeneralRegional/20140227_Regional_GDP.html

27. de Morais C, Oliveira B, Afonso C, et al. (2013) Nutritional risk of European elderly. Eur J Clin Nutr 67, 1215-1219.

28. Santos DM, Rodrigues SS, Oliveira BM, et al. (2014) Dietary availability in elderly Portuguese households. Public Health Nutr 4, 1-17.

29. Lutoslawska G, Malara M, Tomaszewski P, et al. (2014) Relationship between the percentage of body fat and surrogate indices of fatness in male and female Polish active and sedentary students. J Physiol Anthropol 33, 1-6.

30. Carmienke S, Freitag MH, Pischon T, et al. (2013) General and abdominal obesity parameters and their combination in relation to mortality: a systematic review and meta-regression analysis. Eur J Clin Nutr 67, 573-585.

31. European Food Safety Authority (2014) Guidance on the EU Menu methodology. EFSA J 12, 3944.

32. Wądołowska L, Cichon R, Słowińska MA, et al. (2004) Comparison of eating habits on the basis of single and triple dietary interviews. Pol J Food Nutr Sci 13/54, 313-320. 